\title{
Mediating Role of Decentering in the Associations between Self-Reflection, Self-Rumination, and Depressive Symptoms
}

\author{
Masaki Mori ${ }^{1,2}$, Yoshihiko Tanno² \\ ${ }^{1}$ Research Fellow of the Japan Society for the Promotion of Science, Tokyo, Japan \\ ${ }^{2}$ Department of Life Sciences, Graduate School of Arts and Sciences, The University of Tokyo, Tokyo, Japan \\ Email: mmori@beck.c.u-tokyo.ac.jp
}

Received 10 March 2015; accepted 13 April 2015; published 16 April 2015

Copyright $@ 2015$ by authors and Scientific Research Publishing Inc.

This work is licensed under the Creative Commons Attribution International License (CC BY).

http://creativecommons.org/licenses/by/4.0/

(c) (i) Open Access

\section{Abstract}

Theorists have suggested that self-focused attention has adaptive and maladaptive aspects and have proposed self-rumination and self-reflection. Previous research on self-focus and mindfulness have shown that self-rumination increases depression and counteracts decentering which is the capacity to take a detached view of one's thoughts and emotions. On the contrary, although self-reflection was defined as an adaptive type of self-focus, its contents or mode have not been examined, and the mechanism of its contribution to psychological adjustment is still not well understood. Hence, we explored the function of self-reflection in relation to decentering to elucidate its adaptivity. Two-hundred and forty-nine Japanese undergraduate students participated in our cross-sectional questionnaire study. Mediation analysis indicated that individuals with higher levels of self-reflection showed more decentering and less depressive symptoms while self-ruminative participants showed less decentering and more depressive symptoms. This result suggests that self-reflection involves decentered self-focused attention, and its adaptive function appears when self-reflection leads to increased decentering.

\section{Keywords}

Self-Reflection, Self-Rumination, Depression, Decentering, Mediating Role

\section{Introduction}

Self-focused attention is theoretically necessary for self-regulation and can produce constructive outcomes such as emotion regulation and success in problem-solving (Carver \& Scheier, 1990; Martin \& Tesser, 1996). On the 
other hand, a large body of research has highlighted its association with mental health problems, including exacerbated depression, anxiety, and dysphoric moods (Mor \& Winquist, 2002; Pyszczynski \& Greenberg, 1987; Smith \& Greenberg, 1981). In particular, previous research has consistently indicated that negative and persistent self-focus is a serious cognitive risk factor for depression (Just \& Alloy, 1997; Nolen-Hoeksema, 2000; Nolen-Hoeksema, Wisco, \& Lyubomirsky, 2008). To distinguish the adaptive from the maladaptive aspects of selffocus, Trapnell and Campbell (1999) proposed two subtypes of self-focused attention: self-rumination and selfreflection. Self-rumination is proposed as a maladaptive type defined as negative and chronic self-focus motivated by threat, loss, and injustice to the self. Previous studies showed links between self-rumination and unconstructive outcomes such as exacerbated depression (Takano \& Tanno, 2009), decreased subjective happiness (Elliott \& Coker, 2008), low levels of perspective taking (Joireman, Parrot, \& Hammersla, 2002), and impaired interpersonal skills (Takano, Sakamoto, \& Tanno, 2011). Self-reflection, contrary to self-rumination, is proposed as an adaptive type of self-focus motivated by epistemic curiosity in the self. Previous research has indicated that self-reflection is associated with adaptive outcomes such as decreased depressive symptoms (Takano \& Tanno, 2009), increased subjective happiness (Elliott \& Coker, 2008), clear self-knowledge (Şimşek, Ceylandağ, \& Akcan, 2013), and autonomous self-regulation (Thomsen, Tønnesvang, Schnieber, \& Olesen, 2011). However, since the contents or mode of self-reflective thinking are still unclear, the detailed mechanism of its contribution to psychological adjustments is not well understood. In the present study, we explored the function of self-reflection in relation to decentering (Teasdale et al., 2002) to elucidate its adaptivity.

The difference between the maladaptive and adaptive functions of self-rumination and self-reflection may come from their different relationships with decentering, which has emerged from mindfulness theory. Mindfulness-based depression intervention aims at acquiring the ability to direct and maintain attention towards the present moment in an open and non-judgmental way, and a number of empirical studies have reported that mindfulness-based intervention resulted in reduction of rumination (Campbell, Labelle, Bacon, Faris, \& Carlson, 2012; Shapiro, Brown, \& Biegel, 2007; Shapiro, Oman, Thoresen, Plante, \& Flinders, 2008) and depression (Hofmann, Sawyer, Witt, \& Oh, 2010; Teasdale, Segal, \& Williams, 1995). Mindfulness theory proposed that the effects of mindfulness-based intervention on depression are due to increased decentering (Teasdale et al., 2002), which is the ability to objectively observe one's internal experiences such as thoughts and feelings. The core concept of decentering, rather than changing the content of one's thoughts, is changing one's relationship to one’s thoughts (Fresco, Moore, van Dulmen, Segal, Ma, Teasdale, \& Williams, 2007; Teasdale et al., 2002). Theorists have suggested that decentering counteracts rumination since decentered individuals are aware of their ruminative thinking and can relate differently to ruminative thoughts, and decreased rumination through decentering leads to reduction of depression (Fresco, Moore et al., 2007; Teasdale et al., 2002). Consistent with the theory, studies have consistently found this negative association between decentering and rumination (Fresco, Moore et al., 2007; Kurihara, Hasegawa, \& Nedate, 2010). In addition, recent research has reported that decentering is negatively associated with depression (Fresco, Moore et al., 2007; McCracken, Barker, \& Chilcot, 2014) and related to protection against relapse of major depression (Fresco, Segal, Buis, \& Kennedy, 2007). Therefore, decentering is considered to indirectly reduce depression by decreasing rumination. The previous findings and theory mentioned above, which indicate that decentering counteracts ruminative self-focus, also raise a suggestion for how trait self-rumination increases depression. That is, individuals with a tendency towards self-rumination conceptually have difficulty spontaneously taking a decentered perspective and are consequently unable to avoid depression (Fresco, Moore et al., 2007; Teasdale et al., 2002). Indeed, previous research has indicated that ruminative people are motivated for rumination by the belief that ruminative thinking is helpful for problem solving, and they voluntarily engage in maladaptive rumination (Papageorgiou \& Wells, 2001). Although these lead to an implication that trait self-rumination decreases decentered perspective and indirectly increases depression, such causality has been rarely examined in the context of psychological treatment, which emphasizes reduction of maladaptive factors. Therefore, the present study examined the hypothesis that self-rumination has a direct association with depression, which is mediated by reduced decentering.

In contrast to self-rumination, self-reflection is considered to be associated with increased decentering. Following Trapnell and Campbell (1999), the thought contents of self-reflective people can conceptually be both positive and negative (e.g., I love analyzing why I do things) and are not always emotionally loaded (e.g., I'm very self-inquisitive by nature). This suggests that individuals high in self-reflection may encounter negative thoughts or emotions just as low self-reflective people do. Nevertheless, prior studies reported the negative association between self-reflection and depressive symptoms (Takano \& Tanno, 2009) and suggested that self- 
reflection enhances the emotion-regulation function of problem-solving behavior against stressful situations (Mori, Takano, \& Tanno, 2015). The above suggestions lead a hypothesis that individuals high in self-reflection can objectively focus on their inner experiences even if they are negatively loaded. Thus, in contrast to selfrumination, self-reflection may be positively associated with decentering. In fact, one previous study reported a positive correlation between self-reflection and decentering ( $r=.42$, Lau et al., 2006) with the Toronto Mindfulness Scale (TMS). Decentering can be considered to mediate the relationships between self-reflection and its benefits. If individuals high in self-reflection have higher decentered perspective, they can observe themselves objectively and clarify their self-knowledge without negative bias (Şimşek et al., 2013), properly regulate themselves against intrusive or ruminative thoughts (Thomsen et al., 2011), and feel lower depressed mood (Takano \& Tanno, 2009). We then hypothesized that self-reflection is directly associated with low levels of depression, and this association is mediated by decentering.

It should be noted that the TMS is designed to be administered after meditating (Lau et al., 2006). However, the present study focuses on whether individuals high in self-reflection can spontaneously take a decentered perspective in everyday life. Hence, we employed the Experiences Questionnaire (EQ; Fresco, Moore et al., 2007), which asks participants to indicate whether they took a decentered perspective in "recent events". Thus, the first aim of the present study is to confirm the previous finding (i.e., positive association between selfreflection and decentering; Lau et al., 2006) with another decentering measurement (i.e., the EQ). The second and main purpose of the present study is to distinguish between maladaptive and adaptive functions of selffocused attention by examining the mediating role of decentering in the relationships among self-reflection, selfrumination, and depressive symptoms. Our hypothesis states that self-reflection is associated with low levels of depressive symptoms, a relationship mediated by high levels of decentering. On the other hand, self-rumination may have a relationship with more depressive symptoms, which is mediated by low levels of decentering.

\section{Materials and Method}

\subsection{Participants}

Two-hundred and forty-nine Japanese undergraduate students (136 men, 113 women) completed a questionnaire packet in introductory psychology classes at two Japanese universities. Their mean age was 19.6 years $(S D=$ 2.1).

\subsection{Instruments}

\subsubsection{Self-Rumination and Self-Reflection}

Tendencies towards self-rumination and self-reflection were assessed using the Rumination-Reflection Questionnaire (RRQ; Trapnell \& Campbell, 1999). The RRQ consists of two subscales focusing on self-rumination and self-reflection. Each subscale contains 12 items rated on a 5-point scale ranging from 1 (strongly disagree) to 5 (strongly agree). In this study, the Japanese version of the scale (Takano \& Tanno, 2008) was used; this version exhibited good internal consistency ( $\alpha=.87$ for self-rumination; $\alpha=.88$ for self-reflection).

\subsubsection{Decentering}

To assess decentering, we used the Experiences Questionnaire (Fresco, Moore et al., 2007). The EQ consists of two subscales assessing decentering (13 items) and rumination (7 items), and each item was rated on a 5-point scale ranging from 1 (never) to 5 (all the time). The rumination subscale of the EQ was included as a control against response bias (Fresco, Moore et al., 2007); the present study analyzed not the rumination subscale of the EQ but, rather, the self-rumination subscale of the RRQ. The EQ does not assess dispositional decentering ability; it provides how the answerer took a decentered perspective in "recent experiences". In the Japanese sample, confirmatory factor analyses revealed that the Japanese version of the decentering subscale consists of 10 items (Kurihara et al., 2010). A prior study has shown that the Japanese version of the decentering subscale had adequate internal consistency $(\alpha=.78)$ and validity (Kurihara et al., 2010); the same internal consistency was found in the present study $(\alpha=.78)$.

\subsubsection{Depressive Symptoms}

In order to measure depressive symptoms, we administered the Beck Depression Inventory second edition (BDI-II; 
Beck, Steer, \& Brown, 1996). The BDI-II consists of 21 items, each rated on a 4-point scale (from 0 to 3). We used the Japanese version of the scale (Kojima et al., 2002) with an alpha coefficient of .89.

\subsection{Procedure}

Prior to data collection, students were informed that participation was voluntary and that their answers were confidential and would not be connected to their school records. We collected data from participants who signed the informed consent form. All data were analyzed with the Statistical Package for Social Sciences (SPSS, version 22.0). To test the mediation model, we used the SPSS macro script (MEDIATE; Hayes \& Preacher, 2014).

\section{Results}

Descriptive statistics and correlations between the study variables are provided in Table 1. Although self-rumination was positively associated with depressive symptoms $(r=.54, p<.001)$, self-reflection had no association with depressive symptoms $(r=.10, p=.124)$. Decentering was negatively associated with depressive symptoms $(r=-.45, p<.001)$. These results were consistent with previous research (Fresco, Moore et al., 2007; Trapnell \& Campbell, 1999). Consistent with our prediction and confirming previous findings (Lau et al., 2006), decentering was correlated positively with self-reflection $(r=.24, p<.001)$ and negatively with self-rumination $(r=$ $-.37, p<.001)$. Self-reflection and self-rumination were correlated with each other $(r=.26, p<.001)$, which may be because of their shared variance of self-consciousness (Trapnell \& Campbell, 1999).

Following Baron and Kenny (1986), we next tested the mediation model in which depressive symptoms are predicted by self-reflection and self-rumination and these relationships are mediated by decentering (Figure 1). To test the total effects on depressive symptoms, we conducted a multiple regression analysis in which selfreflection and self-rumination predicted depressive symptoms, controlling for gender. Self-reflection did not predict depressive symptoms ( $c_{1}$ path: $B=-.04, S E=.05, t=-.79, p=.428$ ), but self-rumination predicted them significantly ( $c_{2}$ path: $B=.57, S E=.06, t=9.93, p<.001$ ). The covariate (i.e., gender) did not predict the depressive symptoms $(B=-.30, \mathrm{SE}=.86, t=-0.35, p=.724)$. Adjusted $\mathrm{R}^{2}$ of this regression equation was significant (adjusted $\mathrm{R}^{2}=.29, F(3,245)=34.07, p<.001$ ). We then conducted a multiple regression analysis predicting

Table 1. Descriptive statistics and correlations.

\begin{tabular}{|c|c|c|c|c|c|}
\hline & Mean & SD & 1. & 2. & 3. \\
\hline 1. depressive symptoms & 11.7 & 8.0 & - & & \\
\hline 2. decentering & 27.6 & 5.5 & $-.45^{* * *}$ & - & \\
\hline 3. self-reflection & 38.4 & 8.2 & .10 & $.24^{* * *}$ & - \\
\hline 4. self-rumination & 42.6 & 7.7 & $.54^{* * *}$ & $-.37^{* * *}$ & $.26^{* * *}$ \\
\hline
\end{tabular}

Note: Analysis includes 249 participants. ${ }^{* * *} p<.001$.

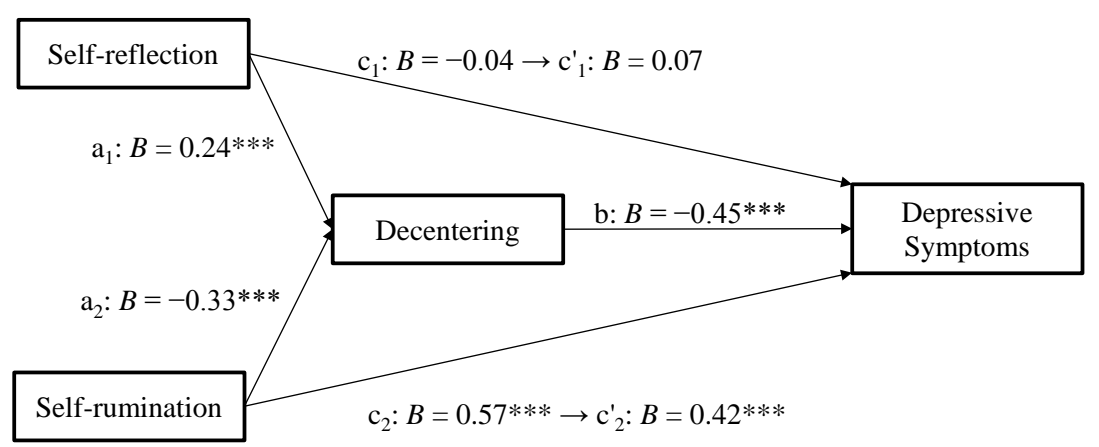

Figure 1. The estimated mediation model in which self-reflection and self-rumination associated with depressive symptoms directly and indirectly via decentering. Note: Unstandardized coefficients $(B)$ are presented. All analyses include a covariate (i.e., gender), but it is not shown for ease of presentation. ${ }^{* * *} p<.001$. 
decentering with the same independent variables as in previous regression equation. The results showed that self-reflection significantly predicted higher decentering ( $\mathrm{a}_{1}$ path: $B=.24, S E=.04, t=6.34, p<.001$ ), while self-rumination significantly predicted lower decentering ( $\mathrm{a}_{2}$ path: $B=-.33, S E=.04, t=-8.05, p<.001$ ). Gender did not predict decentering $(B=.29, S E=.61, t=0.48, p=.634)$. Adjusted $\mathrm{R}^{2}$ of this regression equation was significant (adjusted $\mathrm{R}^{2}=.25, F(3,245)=28.22, p<.001$ ). To test the association between the mediator and depressive symptoms, we calculated a final regression equation in which depressive symptoms were predicted by self-reflection, self-rumination, and decentering, controlling for gender. The results showed nonsignificant main effects of self-reflection ( $c_{1}^{\prime}$ path: $B=.07, S E=.06, t=1.23, p=.220$ ) and significant main effect of self-rumination ( $c_{2}^{\prime}$ path: $B=.42, S E=.06, t=6.87, p<.001$ ) and decentering (b path: $B=-.45, S E$ $=.09, t=-5.34, p<.001)$. Gender had no association with depressive symptoms $(B=-.17, S E=.81, t=-.21, p$ $=.834$ ). This regression equation showed significant and adequately large adjusted $\mathrm{R}^{2}$ (adjusted $\mathrm{R}^{2}=.36, F(4$, $244)=35.55, p<.001)$.

In order to test the indirect effects of self-reflection and self-rumination on depressive symptoms via decentering, we estimated the $95 \%$ confidential intervals of these indirect effects using a bias-corrected bootstrap method with 10,000 resamples according to Hayes and Preacher (2014). The results showed that the indirect effect of self-reflection was significantly different from zero at $p<.05$ (point estimate $=-.11 ; 95 \%$ CI $[-.18,-.06]$ ) and the significant indirect effect of self-rumination (point estimate $=.15$; 95\% CI $[.08, .24]$ ), suggesting that individuals high in self-reflection show lower depressive symptoms via higher decentering while individuals high in self-rumination show higher depressive symptoms via lower decentering.

\section{Discussion}

The present results largely support our hypotheses. The indirect association of self-reflection with lower depressive symptoms through higher decentering was significant. However, the direct association between self-reflection and depressive symptoms did not reach significance without controlling for decentering, which is inconsistent with our hypothesis. The significant indirect association of self-rumination through lower decentering suggests that the maladaptive role of self-rumination is partially mediated by decentering. This result supports the theory that rumination counteracts decentering, which can reduce depression. The direct association of selfrumination with depressive symptoms also remained after controlling for the indirect association.

The negative indirect association of self-reflection with depressive symptoms via decentering supports the notion that self-reflection is an adaptive form of self-focus (Trapnell \& Campbell, 1999). This result suggests that individuals high in self-reflection can acquire a decentered perspective, and this ability of decentering is a source of the adaptivity of self-reflection. However, the direct associations between self-reflection and depression were not significant regardless of whether or not we controlled for decentering. The direct relationship between selfreflection and depression is instable among previous studies. For example, one previous study reported a negative association between self-reflection and depression (Takano \& Tanno, 2009) while others reported non-significant correlation (Siegle, Moore, \& Thase, 2004; Trapnell \& Campbell, 1999). These mixed results may be because these previous studies did not assess indirect association through decentering. In addition, the prior research indicating the negative association between self-reflection and depression (Takano \& Tanno, 2009) also suggested that self-reflective thinking can turn into self-ruminative thinking. One possibility is that self-reflection becomes adaptive only when it leads to increased decentering and maladaptive when it leads to decreased decentering, turning into negative and ruminative thinking. Although one prior study suggested that self-reflection enhances problem solving (Mori et al., 2015), others have suggested that self-reflective thinking turns into self-ruminative thinking when reflective individuals' attempts to understand and analyze their problems fail to generate solutions (Miranda \& Nolen-Hoeksema, 2007; Takano \& Tanno, 2009). Thus, it can be speculated that individuals high in self-reflection can spontaneously take a decentered perspective but are unable to maintain it when they fail in their problem-solving attempts. If conducting an intervention to encourage self-reflective people to maintain their decentered perspectives in spite of failed problem-solving attempts, self-reflection may exhibit adaptivity even after their failures.

Contrary to self-reflection, self-rumination was indirectly associated with more depression through low levels of decentering. This result is consistent with the theoretical notion that self-rumination is antithetical to decentering and that decentering is an important factor for treatment of depression (Fresco, Moore et al., 2007; Teasdale et al., 2002). However, the direct association between self-rumination and depressive symptoms remained after controlling for decentering, which means that self-rumination is associated with depressive symptoms 
without reduction of decentering. One possible explanation for this is that other variables not included in the present model mediate the relationship between self-rumination and depressive symptoms. Indeed, previous researchers indicated that rumination is associated with reduction in social support (Flynn, Kecmanovic, \& Alloy, 2010) and poor problem-solving ability in interpersonal (Lyubomirsky \& Nolen-Hoeksema, 1995; Lyubomirsky, Tucker, Caldwell, \& Berg, 1999) and academic domains (Lyubomirsky, Kasri, \& Zehm, 2003) and that insufficient social support and poor problem-solving ability are considered to increase depression (Haaga, Fine, Terrill, Stewart, \& Beck, 1995; Nolen-Hoeksema \& Davis, 1999). These unconstructive outcomes can be considered to mediate the association between self-rumination and depressive symptoms. Although previous research suggested that problem-solving ability is also associated with decentering, and, thus, impaired problem solving may be partially explained by reduction of decentering (Ostafin \& Kassman, 2012), future research needs to examine the mediating role of these unconstructive outcomes associated with rumination. Another possible explanation is that the remaining direct association may have been due to the features of self-rumination other than decentering inability. In the present study, we treated self-rumination as a variable theoretically antithetical to decentering (Fresco, Moore et al., 2007; Teasdale et al., 2002). Hence, we did not estimate the interaction between selfrumination and decentering, assuming that the scores would negatively co-vary. However, self-rumination may have characteristics other than inability to take a decentered perspective. For instance, self-rumination may also theoretically involve chronicity, negativity, and invasiveness (Trapnell \& Campbell, 1999). Certainly, decentering can contribute to objectively observing ruminative thinking, which is negative, chronic, and invasive, and can reduce the effect of ruminative thinking on depression. Nevertheless, decentering inability and other selfrumination features may independently vary; therefore, such features may have affected depressive symptoms independently from decentering. To fully disentangle this possibility, future research must decompose selfrumination into negativity, repetitiveness, invasiveness, and decentering inability and test the effect of each feature on depression.

The present study has some limitations. First, we employed a cross-sectional design. Although we assumed that self-focused attention causes the change in decentering and then measured the level of trait self-focus, which is stable, and level of decentering in "recent events", which is more unstable than level of trait decentering ability, we cannot disentangle such causal relationships with a cross-sectional design. Since the present study assumed a mediation model, future research will require a longitudinal study with a three-wave design or an experimental study. Another limitation is a sampling issue. In the present study, participants were non-clinical undergraduate students. This constrains generalizability of our findings. In particular, seriously depressed people (e.g., depressed patients) theoretically have difficulty taking a decentered perspective (Teasdale et al., 2002). Therefore, spontaneous decentering and the indirect association of self-reflection on depression may not be observable in depressed patients. The results need to be replicated in clinical samples and the general population.

\section{Conclusion}

In conclusion, the present study contributes to the literature by providing insight into the adaptivity of self-focus. Our results demonstrate that reflective self-focus is indirectly associated with low level of depressive symptoms through high decentering and thus supports the importance of decentering when considering the feature of self-reflection. These results suggest that self-reflection involves decentered self-focused attention. However, a prior study suggested that self-reflection contributes to problem solving (Mori et al., 2015), which is a selfregulatory behavior actively aimed at resolving or reducing the negative self-discrepancy between the ideal and real self (Carver \& Sheier, 1982, 1990). If self-reflection contributes to this active and direct coping style, it is inconsistent, at first sight, with the present finding that self-reflection is associated with decentering, which is the ability to objectively observe negative self-discrepancy and not to judge whether the discrepancy is good or bad. However, recent research indicated that decentered and active self-analyzing resulted in beneficial outcomes such as emotion regulation and increased problem-solving behavior (Ayduk \& Kross, 2010). Thus, it can be speculated that self-reflection is characterized as decentered and active self-focused attention aimed at problem solving. To test this notion, future research requires further explorations such as clarifying the contents and valence of self-reflective thinking and how or when self-reflection occurs.

\section{Acknowledgements}

We are grateful to Seiji Yamagami for his support with data collection. 


\section{References}

Ayduk, O., \& Kross, E. (2010). From a Distance: Implications of Spontaneous Self-Distancing for Adaptive Self-Reflection. Journal of Personality and Social Psychology, 98, 809-829. http://dx.doi.org/10.1037/a0019205

Baron, R. M., \& Kenny, D. A. (1986). The Moderator-Mediator Variable Distinction in Social Psychological Research: Conceptual, Strategic, and Statistical Considerations. Journal of Personality and Social Psychology, 51, 1173-1182. http://dx.doi.org/10.1037/0022-3514.51.6.1173

Beck, A. T., Steer, R. A., \& Brown, G. K. (1996). Manual for the Beck Depression Inventory (2nd ed.). San Antonio, TX: Psychological Cooperation.

Campbell, T. S., Labelle, L. E., Bacon, S. L., Faris, P., \& Carlson, L. E. (2012). Impact of Mindfulness-Based Stress Reduction (MBSR) on Attention, Rumination and Resting Blood Pressure in Women with Cancer: A Waitlist-Controlled Study. Journal of Behavioral Medicine, 35, 262-271. http://dx.doi.org/10.1007/s10865-011-9357-1

Carver, C. S., \& Scheier, M. F. (1982). Control Theory: A Useful Conceptual Framework for Personality-Social, Clinical, and Health Psychology. Psychological Bulletin, 92, 111-135. http://dx.doi.org/10.1037/0033-2909.92.1.111

Carver, C. S., \& Scheier, M. F. (1990). Origins and Functions of Positive and Negative Affect: A Control-Process View. Psychological Review, 97, 19-35. http://dx.doi.org/10.1037//0033-295X.97.1.19

Elliott, I., \& Coker, S. (2008). Independent Self-Construal, Self-Reflection, and Self-Rumination: A Path Model for Predicting Happiness. Australian Journal of Psychology, 60, 127-134. http://dx.doi.org/10.1080/00049530701447368

Flynn, M., Kecmanovic, J., \& Alloy, L. B. (2010). An Examination of Integrated Cognitive-Interpersonal Vulnerability to Depression: The Role of Rumination, Perceived Social Support, and Interpersonal Stress Generation. Cognitive Therapy and Research, 34, 456-466. http://dx.doi.org/10.1007/s10608-010-9300-8

Fresco, D. M., Moore, M. T., van Dulmen, M. H. M., Segal, Z. V, Ma, S. H., Teasdale, J. D., \& Williams, J. M. G. (2007). Initial Psychometric Properties of the Experiences Questionnaire: Validation of a Self-report Measure of Decentering. Behavior Therapy, 38, 234-246. http://dx.doi.org/10.1016/j.beth.2006.08.003

Fresco, D. M., Segal, Z. V, Buis, T., \& Kennedy, S. (2007). Relationship of Posttreatment Decentering and Cognitive Reactivity to Relapse in Major Depression. Journal of Consulting and Clinical Psychology, 75, 447-455. http://dx.doi.org/10.1037/0022-006X.75.3.447

Haaga, D. A. F., Fine, J. A., Terrill, D. R., Stewart, B. L., \& Beck, A. T. (1995). Social Problem-Solving Deficits, Dependency, and Depressive Symptoms. Cognitive Therapy and Research, 19, 147-158. http://dx.doi.org/10.1007/BF02229691

Hayes, A. F., \& Preacher, K. J. (2014). Statistical Mediation Analysis with a Multi-Categorical Independent Variable. British Journal of Mathematical and Statistical Psychology, 67, 451-470. http://dx.doi.org/10.1111/bmsp.12028

Hofmann, S. G., Sawyer, A. T., Witt, A. A, \& Oh, D. (2010). The Effect of Mindfulness-Based Therapy on Anxiety and Depression: A Meta-Analytic Review. Journal of Consulting and Clinical Psychology, 78, 169-183. http://dx.doi.org/10.1037/a0018555

Joireman, J., Parrott, L., \& Hammersla, J. (2002). Empathy and the Self-Absorption Paradox: Support for the Distinction between Self-Rumination and Self-Reflection. Self and Identity, 1, 53-65. http://dx.doi.org/10.1080/152988602317232803

Just, N., \& Alloy, L. B. (1997). The Response Styles Theory of Depression: Tests and an Extension of the Theory. Journal of Abnormal Psychology, 106, 221-229. http://dx.doi.org/10.1037/0021-843X.106.2.221

Kojima, M., Furukawa, T. A., Takahashi, H., Kawai, M., Nagaya, T., \& Tokudome, S. (2002). Cross-Cultural Validation of the Beck Depression Inventory-II in Japan. Psychiatry Research, 110, 291-299. http://dx.doi.org/10.1016/S0165-1781(02)00106-3

Kurihara, A., Hasegawa, A., \& Nedate, K. (2010). Development of the Japanese Version of the Experiences Questionnaire and Examination of Its Reliability and Validity. The Japanese Journal of Personality, 19, 174-177. http://dx.doi.org/10.2132/personality.19.174

Lau, M. A., Bishop, S. R., Segal, Z. V., Buis, T., Anderson, N. D., Carlson, L. et al. (2006). The Toronto Mindfulness Scale: Development and Validation. Journal of Clinical Psychology, 62, 1445-1467. http://dx.doi.org/10.1002/jclp.20326

Lyubomirsky, S., \& Nolen-Hoeksema, S. (1995). Effects of Self-Focused Rumination on Negative Thinking and Interpersonal Problem Solving. Journal of Personality and Social Psychology, 69, 176-190.

http://dx.doi.org/10.1037/0022-3514.69.1.176

Lyubomirsky, S., Kasri, F., \& Zehm, K. (2003). Dysphoric Rumination Impairs Concentration on Academic Tasks. Cognitive Therapy and Research, 27, 309-330. http://dx.doi.org/10.1023/A:1023918517378

Lyubomirsky, S., Tucker, K. L., Caldwell, N. D., \& Berg, K. (1999). Why Ruminators Are Poor Problem Solvers: Clues from the Phenomenology of Dysphoric Rumination. Journal of Personality and Social Psychology, 77, 1041-1060. 
http://dx.doi.org/10.1037/0022-3514.77.5.1041

Martin, L., \& Tesser, A. (1996). Some Ruminative Thoughts. In R. S. Wyer (Ed.), Ruminative Thoughts (pp. 1-47). Hillsdale, NJ: Erlbaum.

McCracken, L. M., Barker, E., \& Chilcot, J. (2014). Decentering, Rumination, Cognitive Defusion, and Psychological Flexibility in People with Chronic Pain. Journal of Behavioral Medicine, 37, 1215-1225. http://dx.doi.org/10.1007/s10865-014-9570-9

Miranda, R., \& Nolen-Hoeksema, S. (2007). Brooding and Reflection: Rumination Predicts Suicidal Ideation at 1-Year Follow-Up in a Community Sample. Behaviour Research and Therapy, 45, 3088-3095. http://dx.doi.org/10.1016/j.brat.2007.07.015

Mor, N., \& Winquist, J. (2002). Self-Focused Attention and Negative Affect: A Meta-Analysis. Psychological Bulletin, 128, 638-662. http://dx.doi.org/10.1037/0033-2909.128.4.638

Mori, M., Takano, K., \& Tanno, Y. (2015). Role of Self-Focus in the Relationship between Depressed Mood and Problem Solving. Motivation and Emotion, Advance Online Publication. http://dx.doi.org/10.1007/s11031-015-9486-X

Nolen-Hoeksema, S. (2000). The Role of Rumination in Depressive Disorders and Mixed Anxiety/Depressive Symptoms. Journal of Abnormal Psychology, 109, 504-511. http://dx.doi.org/10.1037/0021-843X.109.3.504

Nolen-Hoeksema, S., \& Davis, C. G. (1999). “Thanks for Sharing That”: Ruminators and Their Social Support Networks. Journal of Personality and Social Psychology, 77, 801-814. http://dx.doi.org/10.1037/0022-3514.77.4.801

Nolen-Hoeksema, S., Wisco, B. E., \& Lyubomirsky, S. (2008). Rethinking Rumination. Perspectives on Psychological Science, 3, 400-424. http://dx.doi.org/10.1111/j.1745-6924.2008.00088.x

Ostafin, B. D., \& Kassman, K. T. (2012). Stepping out of History: Mindfulness Improves Insight Problem Solving. Consciousness and Cognition, 21, 1031-1036. http://dx.doi.org/10.1016/j.concog.2012.02.014

Papageorgiou, C., \& Wells, A. (2001). Positive Beliefs about Depressive Rumination: Development and Preliminary Validation of a Self-Report Scale. Behavior Therapy, 32, 13-26. http://dx.doi.org/10.1016/S0005-7894(01)80041-1

Pyszczynski, T., \& Greenberg, J. (1987). Self-Regulatory Perseveration and the Depressive Self-Focusing Style: A SelfAwareness Theory of Reactive Depression. Psychological Bulletin, 102, 122-138. http://dx.doi.org/10.1037/0033-2909.102.1.122

Shapiro, S. L., Brown, K. W., \& Biegel, G. M. (2007). Teaching Self-Care to Caregivers: Effects of Mindfulness-Based Stress Reduction on the Mental Health of Therapists in Training. Training and Education in Professional Psychology, 1, 105-115. http://dx.doi.org/10.1037/1931-3918.1.2.105

Shapiro, S. L., Oman, D., Thoresen, C. E., Plante, T. G., \& Flinders, T. (2008). Cultivating Mindfulness: Effects on WellBeing. Journal of Clinical Psychology, 64, 840-862. http://dx.doi.org/10.1002/jclp.20491

Siegle, G. J., Moore, P. M., \& Thase, M. E. (2004). Rumination: One Construct, Many Features in Healthy Individuals, Depressed Individuals, and Individuals with Lupus. Cognitive Therapy and Research, 28, 645-668. http://dx.doi.org/10.1023/B:COTR.0000045570.62733.9f

Şimşek, Ö. F., Ceylandağ, A. E., \& Akcan, G. (2013). The Need for Absolute Truth and Self-Rumination as Basic Suppressors in the Relationship between Private Self-Consciousness and Mental Health. The Journal of General Psychology, 140, 294-310. http://dx.doi.org/10.1080/00221309.2013.831804

Smith, T. W., \& Greenberg, J. (1981). Depression and Self-Focused Attention. Motivation and Emotion, 5, 323-331. http://dx.doi.org/10.1007/BF00992551

Takano, K., \& Tanno, Y. (2008). Development of Japanese-Version Rumination-Reflection Questionnaire. The Japanese Journal of Personality, 16, 259-261. http://dx.doi.org/10.2132/personality.16.259

Takano, K., \& Tanno, Y. (2009). Self-Rumination, Self-Reflection, and Depression: Self-Rumination Counteracts the Adaptive Effect of Self-Reflection. Behavior Research and Therapy, 47, 260-264. http://dx.doi.org/10.1016/j.brat.2008.12.008

Takano, K., Sakamoto, S., \& Tanno, Y. (2011). Ruminative and Reflective Forms of Self-Focus: Their Relationships with Interpersonal Skills and Emotional Reactivity under Interpersonal Stress. Personality and Individual Differences, 51, 515520. http://dx.doi.org/10.1016/j.paid.2011.05.010

Teasdale, J. D., Moore, R. G., Hayhurst, H., Pope, M., Williams, S., \& Segal, Z. V. (2002). Metacognitive Awareness and Prevention of Relapse in Depression: Empirical Evidence. Journal of Consulting and Clinical Psychology, 70, 275-287. http://dx.doi.org/10.1037/0022-006X.70.2.275

Teasdale, J. D., Segal, Z., \& Williams, J. M. G. (1995). How Does Cognitive Therapy Prevent Depressive Relapse and Why Should Attentional Control (Mindfulness) Training Help? Behaviour Research and Therapy, 33, 25-39. http://dx.doi.org/10.1016/0005-7967(94)E0011-7

Thomsen, D. K., Tønnesvang, J., Schnieber, A., \& Olesen, M. H. (2011). Do People Ruminate Because They Haven’t Di- 
gested Their Goals? The Relations of Rumination and Reflection to Goal Internalization and Ambivalence. Motivation and Emotion, 35, 105-117. http://dx.doi.org/10.1007/s11031-011-9209-x

Trapnell, P. D., \& Campbell, J. D. (1999). Private Self-Consciousness and the Five-Factor Model of Personality: Distinguishing Rumination from Reflection. Journal of Personality and Social Psychology, 76, 284-304.

http://dx.doi.org/10.1037/0022-3514.76.2.284 